FACULDADE DE CIÊ NCIAS ECONÔ MICAS DA UFRGS

REESTRUTURAÇÁ O DA PRODUÇÁ O AGRICOLA NO RIO GRANDE DO SUL, DE 1970 A 1996 E UMA ESTIMAÇȦ O PARA 2012 TIAGO WICKSTROM ALVES

A CRIMINALIDADE NA RECIAO METROPOLTANA DE SALVADOR JOSÉ CARRERA FERNANDEZ, LUIZ FERNANDO LOBO

COMPEIITIVIDADE INTERNACIONAL EM SOFTWARE: UM ESTUDO SOBRE A EXPERIÊNCIA DE FLORIANÓ POLIS HOVÉDO NUNES LINS

MODELOS DE ORGANIZAÇẢ O E REPARTIÇẢ O DE RENDAS NA CADEIA PRODUTIVA DO GÁS NATURAL.

HELder QUEIROZ PINTO Jú NIOR, RODOLFO TORRES dOS SANTOS

REGIMES MONETÁ RIOS E DIVIDA PÚ BLICA: UMA ANÁ LISE DE MECANISMOS ALTERNATIVOS DE COORDENAÇÃO MACROECONÓ MICA

manoel Carlos de Castro Pires

ECONOMIA DOS RECURSOS NATURAIS E SEUS INDICADORES DE ESCASSEZ: UMA QUESTÃ O DE SUSTENTABILIDADE ANDREA SALES SOARES DE AZEVEDO MELO

O ECOPROTECIONISMO AGRICOLA NA UNIĀ O EUROPEIA E SEUS POSSIVEIS IMPACTOS SOBRE A ECONOMIA BRASILEIRA Rodrigo daniel Feix, Clá udio R. Fóffano Vasconcelos

PADRÓ ES DE DESENVOLVIMENTO, FUNÇ Ó ES ESTATAIS E ENDIVIDAMENTO NO CAPITALISMO CONTEMPORÁNEO paulo Balanco, Eduardo Costa Pinto

A INTERNACIONALIZAÇÃO DO VAREJO A PARTIR DOS CASOS WAL-MART E CARREFOUR

Armando joảo dalla Costa

UMA ANÁ LISE ECONOMÉTRICA DO FUTEBOL BRASILEIRO ARI Francisco de Araujo JR, Clá udio D. SHIKIDA, LEONARDO M. MONASTERIO

O BRASIL E A ECONOMIA INTERNACIONAL: RECUPERAÇÃ O E DEFESA DA AUTONOMIA NACIONAL

RESENHA DE ALEXANDRE CÉ SAR CUNHA LEITE

REGIMES MONETÁ RIOS: TEORIA E A EXPERIÊNCIA DO REAL ResenHa de Fernando Ferrari Filho

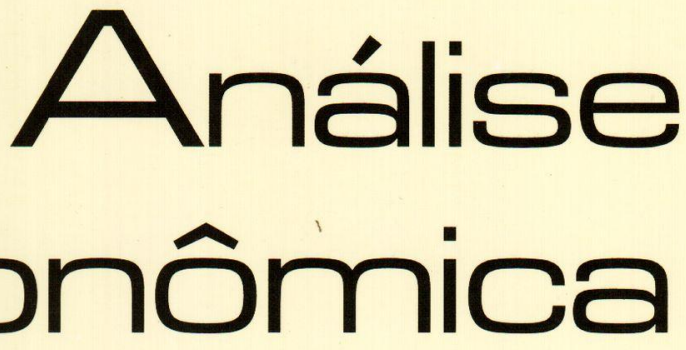


Universidade Federai. do Rio Grande do Sul Reitor: Prof José Carlos Ferraz Hemnemann

Facul dade de Cuéncias Economicas

Diretor: Prof. Gentil Corazza

Ceniro de Estudos f Prequisas Economicas

Diretor: Prof. Lovois de Andrade Miguel

Depariamenio de Crências Economicas

Chefe: Prof Ricardo Dathein

Departamento de Cîncias Coniábeis f A tuaria Chefe: Prof. Ceno Odilo Kops

Curso de Pós-Graduaçó em Economia

Coordenador: Prof. Fernando Ferrari Filho

Curso de Pos-Grainaça em Desenvolvimento RuRAI

Coordenador: Prof. Paulo Dabdab Waquil

Conseluo Eni tokial: André Moreira Cunha (UFRGS) Carlos G. A. Mielitz Netto (UFRGS), Carlos Henrique Hom (UFRGS). Eduardo A. Maldonado Filho (UFRGS). Eleutério F S. Prado (USP), Eugênio Lagemann (UFRGS), Fernando Cardim de Carvalho (UFRJ). Femando Ferrari Filho (UFRGS), Fernando de Holanda Barbosa (FGV/RJ), Flávio Augusto Ziegelmann (UFRGS), Flávio Vasconcellos Comin (UFRGS), Gentil Corazza (UFRGS), Giácomo Balbinot to Neto (UFRGS), Gustavo Franco (PUC/RJ) Hélio Henkin (UFRGS), Jan A. Kregel (UNCTAD), João Rogério Sanson (UFSC), Joaquim Pinto de Andrade (UnB), Júlio César Oliveira (UFRGS), Luiz Estrella Faria (UFRGS), Luiz Paulo Ferreira Nogueról (UFRGS), Marcelo S Portugal (UFRGS), Maria Alice Lahorgue (UFRGS), Octávio Augusto Camargo Conceicão (UFRGS), Paul Davidson (University of Tennessee), Paulo D. Waquil (UFRGS), Pedro C. D. Fonseca (UFRGS), Philip Arestis (University of Cambridge), Ricardo Dathein (UFRGS) Ronald Otto Hillbrecht (UFRGS), Sabino da Silva Porto Jr (UFRGS), Sérgio M. M. Monteiro (UFRGS), Stefano Florissi (UFRGS) e Werner Baer (University of IIIinois at Urbana - Champaign)

Comissão Emroniai: Eduardo Augusto Maldonado Filho, Fernando Ferrari Filho, Hélio Henkin. Marcelo Savino Portugal, Paulo Dabdab Waquil e Sérgio Marley Modesto Monteiro.

EnIrok: Sérgio Marley Modesto Monteiro

Ediror Adjun ro: Hélio Henkin

Secretário: Emerson Douglas Neves

REVISÃo DE IEX ros: Vanete Ricacheski

Emioração: Núcleo de Editoração e Criação da

Gráfica da UFRGS - Janaína Horn e Junia Saedt

Fundador: Prof Antonio Carlos Santos Rosa
Os materiais publicados na revista Análise Econômica são da exclusiva responsabilidade dos autores. É permitida a reprodução total ou parcial dos trabalhos, desde que seja citada a fonte. Aceita-se permuta com revistas congêneres. Aceitam-se, também, livros para divulgacão, elaboraça de resenhas e recensões Toda correspondência: material para publicação (vide normas na terceira capa), assinaturas e permutas devem ser dirigidos ao seguinte destinatário:

Prof. Sérgio Marley Modesto Monteiro Revista Andilse Económica - Av. João Pessoa, 52 CEP 90040-000 PORTO ALEGRE - RS, BRASIL Telefones: (051) $33163513 / 33164164$

Fax: (051) 33163990 - E-mail: rae@vortex ufrgs.br

A Revista Análise Econômica agradece a colaboração dos pareceristas do número 43, abaixo relacionados:

Adalmir Antonio Marquetti

André Moreira Cunha

Carlos José Caetano Bacha

Carlos Mielitz. Netto

Clailton Ataídes de Freitas

Claudio Roberto Fóffano Vasconcelos

Eduardo Ernesto Filippi

Eduardo Pontual Ribeiro

Eleuterio Fernando da Silva Prado

Fernando J Cardim de Carvalho

Fernando Augusto Mansor de Mattos

Fernando Ferrari Filho

Flávio Tosi Feijó

Flavio Vilela Vieira

Francisco Paulo Cipolla

Gentil Corazza

Gíacomo Balbinotto Neto

Helio Henkin

Jefferson Andronio Ramundo Staduto

João de Deus Sicsú Siqueira

José Carrera Fernandes

Leonardo Monteiro Monasterio

Luís Fernando de Paula

Luis Roberto Nascimento

Manoel Carlos de Castro Pires

Octavio Augusto Camargo Conceição

Patrízia Raggi Abdallah

Robson Antonio Grassi

Ronald Otto Hilbrech

Tiago Wickstrom Alves

Tito Belchior Silva Moreira

Análise Econônica

Ano 23, n ${ }^{\circ} 44$, setembro, 2005 - Porto Alegre

Faculdade de Ciências Economicas, UFRGS, 2000

Periodicidade semestral, março e setembro

1. Teoria Econômica - Desenvolvimento Regional -

Economia Agrícola - Pesquisa Teórica e Aplicada -

Periódicos. I.. Brasil

Faculdade de Ciências Econômicas,

Universidade Federal do Rio Grande do SuI

CDD 330.05

CDU $33(81)(05)$ 


\section{Competitividade internacional em Software: um estudo sobre a experiência de Florianópolis}

Hoyêdo Nunes Lins*

Resumo: Exportar software em países menos industrializados é geralmente dificil. Este artigo aborda tal questão, focalizando a experiência do aglomerado de alta tecnologia da região de Florianópolis, que registra a projeção internacional de alguns de seus integrantes. Baseado em pesquisa de campo, o texto desdobra-se em cinco partes, além da introdução e da conclusão. Na primeira explora-se o tema da internacionalização do segmento de software, destacando as dificuldades dos países menos desenvolvidos e a importância da "forma aglomerado" para os setores de alta tecnologia. Na segunda e terceira partes, respectivamente, descrevem-se o aglomerado de alta tecnologia de Florianópolis e os procedimentos da pesquisa de campo. Em seguida, apresentam-se os casos de internacionalização encontrados, caracterizando-os e procurando discernir o papel da "forma aglomerado" em cada um, e depois analisam-se e discutem-se os resultados da pesquisa empírica. Conclui-se assinalando, entre outras coisas, a importância de medidas de promoção que impliquem principalmente suporte financeiro e técnico à internacionalização, essenciais para as firmas estudadas e também, certamente, para o aglomerado como um todo.

Palavras-chave: Exportações de software, Aglomerado de alta tecnologia de Florianópolis, Internacionalização das empresas de software de Florianópolis.

Código JEL: L20, L63.

Abstract: Exporting software in less developed countries is often difficult. Such question is the subject matter of this article, that focuses specifically on the experience of the high technology agglomeration of the Florianópolis area, some members of which have been selling internationally. Based upon field work, the text has five sections, apart from the introduction and the conclusion. In the first one, the general problem of software exporting, particularly in what concerns the less developed countries, and also the importance of agglomerations of firms and institutions for high technology performance, are looked upon. In the second and third sections, respectively, the high technology agglomeration of Florianópolis and the procedures followed in field research are described. Next, the cases of internationalization identified are presented and characterized, and the problem concerning the influence of the agglomeration in such performance is considered. The fifth part analyzes and discusses the materials obtained through

\footnotetext{
Professor do Departamento de Ciências Econômicas da Universidade Federal de Santa Catarina, com participação no Programa de Pós-Graduação em Economia dessa universidade.
} 
the interviews, and the conclusion of the article stresses that, among other things, measures of promotion representing technical and financial support to internationalization would be highly important to the firms studied and, certainly, also to the agglomeration as a whole.

Keywords: Software exports, High technology agglomeration of Florianópolis, Internationalization of software firms of Florianópolis.

JEL Code: L,20,L63.

\section{Introdução}

As atividades de desenvolvimento e produção de software possuem grande destaque na indústria de informática e figuram entre as que mais crescem no mundo. O segmento é amplamente dominado pelas empresas dos países mais industrializados, sobretudo as estadunidenses, uma proeminência observada tanto em desenvolvimento (criação e transformação de programas de computadores) quanto em produção (reprodução de tais programas). Todavia essas atividades ocorrem também fora do eixo que interliga a América do Norte, as estruturas tecnológico-industriais mais fortes da União Européia e o Japão, como indicam experiências de países com menor presença industrial e tecnológica em termos históricos.

A Índia é um bom (talvez o melhor) exemplo de país com destaque no segmento de software situado fora daquele eixo, pela intensidade com que vem atraindo operações de empresas dos Estados Unidos (RAI, 2003) e da Europa (MOST..., 2004) e pela proliferação de novos estabelecimentos principalmente na área de Bangalore. Mas a China também dá passos nesse sentido, despontando como opção para tais empresas (HIGH TECH..., 2002). Na base desses movimentos, vistos não sem inquietação no Ocidente - sobretudo nos Estados Unidos, onde sobressaíram no debate político relacionado às eleições presidenciais de 2004 -, encontra-se a oferta, naqueles países, de uma mão-de-obra muito mais barata e, haja vista os numerosos contingentes de engenheiros formados a cada ano, bastante qualificada (LOHR, 2004).

Entretanto as dificuldades dos países menos industrializados não são pequenas. O próprio perfil do segmento de software impõe-lhes limitações. Os softwares podem ter uso geral (quando são "horizontais", como os processadores de texto) ou específico (caso dos "verticais", para setores definidos) e apresentam-se, desconsiderando a forma "embarcada" em equipamentos, como "pacotes" (isto é, padronizados) ou como produtos que resultam de encomenda, desti- 
nados a clientes e utilizações definidos. Ora, tendo em vista o padrão de concorrência e a estrutura do mercado, softwares "horizontais" e padronizados tendem a ser prerrogativas das maiores empresas, instaladas nos países mais ricos. Para os demais países, pelo menos até recentemente, as possibilidades estariam a se restringir às categorias "vertical" e "sob encomenda", nas quais há espaços de atuação inclusive para empresas de menor porte. Mesmo nesses nichos, contudo, os problemas enfrentados por esses países são consideráveis. Aspectos como capacidade financeira precária representam enormes desvantagens, essa restrição revelando-se especialmente problemática pelo fato de as iniciativas em Pesquisa e Desenvolvimento e o trato com os altos custos de comercialização dependerem das condições de financiamento existentes.

Ainda mais adversas são as circunstâncias que, segundo diferentes estudos, cercam as exportações de software nesses países. E esse é o principal foco de atenção neste artigo, no qual se abordam, especificamente, algumas tentativas de internacionalização protagonizadas no seio do aglomerado de alta tecnologia instalado em Florianópolis.

O objetivo do trabalho é triplo: a) identificar empresas com inserção externa e caracterizar as situações encontradas; b) levantar e analisar os procedimentos que subjazem à penetração em mercados no exterior; c) avaliar a importância da "forma aglomerado" na internacionalização do segmento de software local. O primeiro passo, entretanto, é apresentar um recorte mais preciso da problemáti$\mathrm{ca}$ - as exportações de software - com ênfase na situação dos países menos desenvolvidos. As partes seguintes contêm, pela ordem: uma descrição do aglomerado de alta tecnologia de Florianópolis; a apresentação dos procedimentos da pesquisa de campo; os resultados das entrevistas (realizadas principalmente em empresas) sobre experiências de internacionalização; a análise das informações obtidas; as conclusões.

\section{Software: o Problema da Internacionalização}

As exportações de software pelos países menos industrializados enfrentam via de regra as dificuldades impostas por fatores "internos". Tais fatores referem-se, em primeiro lugar, à estreiteza dos mercados nacionais, uma limitação que reflete nas escalas das empresas e na tendência destas à especialização em atividades de menor valor agregado, envolvendo mão-de-obra de menores salários. Esses fatores dizem igualmente respeito à predominância de sistemas 
educacionais e de formação técnico-profissional que deixam a desejar, uma insuficiência que repercute na qualificação técnica da mão-de-obra; isto é especialmente problemático tendo em vista a necessidade de recursos humanos de elevada qualificação técnica nas atividades voltadas ao desenvolvimento de programas de computador. Os fatores "internos" abrangem também a existência de padrões de qualidade que nem sempre (ou só em poucos casos) favorecem a presença internacional, e, ainda, têm a ver com obstáculos no plano da comercialização.

Esses entraves são amplificados pelas características gerais dessa indústria. Entre os traços mais salientes figuram a dominação e a liderança das empresas estadunidenses nas áreas de sistemas operacionais ou de software "pacote", revelando-se forte a concentração do mercado, como indicam os dados sobre comércio internacional apresentados na Tabela 1 . Percebe-se que o comércio de software é amplamente concentrado no conjunto dos países mais ricos: por exemplo, em 1998, quase 93\% das importações realizados pelos países da Organização para Cooperação e Desenvolvimento Econômico (OCDE) eram provenientes da própria OCDE, com maior destaque individual para os Estados Unidos como origem dos produtos. A situação geral, portanto, tende a ser pouco favorável ao envolvimento de empresas menores e de países menos industrializados na economia do desenvolvimento e da produção de software em escala mundial.

No entanto, existem importantes exemplos de participação de países menos ricos nessa economia. O mais divulgado até o presente momento concerne à Índia, tida como um caso de sucesso, mas o mundo asiático também registra experiências como as de Cingapura, Coréia do Sul e, mais recentemente, China. Na América Latina, pelo menos durante parte da década de 1990, o Chile figurou como exportador de maior expressão, à frente de Argentina e Brasil (Correa, 1996). Fora da Ásia e da América Latina, mas sem representar inserção entre os países mais importantes, nota-se o desempenho de Irlanda e Israel, a primeira tornada base de exportações de software "pacote" por empresas multinacionais interessadas em comercializar na Europa, o segundo ostentando desempenho impulsionado pelos interesses e necessidades referentes à segurança e à defesa nacionais (Fortalecendo..., 2003). Cabe sublinhar que todos esses casos parecem ter em comum o decisivo envolvimento do setor público na promoção das vendas externas. Esse engajamento revela diferentes intensidades $\mathrm{e}$ formas, desde o apoio às atividades de pesquisa e à transferência de tecnologia, até a provisão de infra-estrutura e de facilidades no terreno do crédito. 
Tabela 1: Comércio internacional de produtos de software envolvendo a Organização para Cooperação e Desenvolvimento Econômico (OCDE), em 1998 participação em \% e valores em US $\$$ milhões

\begin{tabular}{l|c||c}
\hline \multicolumn{1}{c|}{ Paises ou regiôes } & Exportações para & Importações desde \\
\hline Paises da OCDE & $\mathbf{8 5 , 4 \%}$ & $\mathbf{9 2 , 8} \%$ \\
Japão & $5,6 \%$ & $2,2 \%$ \\
Estados Unidos & $4,6 \%$ & $28,0 \%$ \\
Canadá & $8,4 \%$ & $1,9 \%$ \\
União Européia & $55,1 \%$ & $58,6 \%$ \\
Paises externos à OCDE & $\mathbf{1 4 , 6 \%}$ & $\mathbf{7 , 2} \%$ \\
Ásia & $7,0 \%$ & $6,8 \%$ \\
Europa & $1,5 \%$ & $0,2 \%$ \\
América do Sul & $3,4 \%$ & $0,0 \%$ \\
Total & $100,0 \%$ & $\mathbf{1 0 0 , 0} \%$ \\
\hline Valor (US\$ milhões) & $\mathbf{9 . 6 7 6}$ & $\mathbf{9 . 0 9 6}$ \\
\hline
\end{tabular}

Fonte: OECD (2000), p. 29

A internacionalização da indústria de software desses países escora-se na combinação de três tipos básicos de estratégias, conforme Correa (1996):

1 - "exportaçōes" de serviços pela sua prestação temporária por quadros técnicos e empresas desses países a clientes no exterior - envolvendo principalmente serviços de programação, essa estratégia marcou profundamente a experiência da India;

2 - "exportações" de serviços de desenvolvimento de softwares, em programas "customizados" a partir de especificações definidas na interação com clientes estrangeiros e em atividades de programação baseadas no envolvimento em vínculos de subcontratação ou em joint-ventures com empresas estrangeiras - países como Taiwan, Cingapura e Chile assistiram à utilização desse tipo de estratégia pelas suas empresas;

3 - exportação efetiva de produtos da indústria, sustentada pela reunião de certas condições vinculadas a financiamento, gestão e comercialização (principalmente envolvendo acesso às redes de distribuição) e por garantias de prestação de serviços pós-venda - empresas de Israel, Irlanda e Chile lançaram mão dessa estratégia.

A experiência indiana, foco de atenção geral na atualidade, merece realce por dois motivos básicos: o dinamismo das suas exportações e as possíveis implicações do perfil prevalecente na indústria de software desse país. 
Sobre o primeiro aspecto, basta indicar que o valor exportado pela Índia em software, incrustado essencialmente em serviços, passou de US $\$ 131,2$ milhões em 1992 para US $\$ 7,8$ bilhões em 20012002 , a orientação exportadora desse setor naquele país traduzindo-se claramente no fato de, nesse último período, as receitas de exportações terem superado em três vezes as das vendas domésticas (D'Costa, 2003). O outro aspecto é indissociável do próprio peso dessas exportações. De um lado, o dinamismo do setor de software não se propagou em outros setores da economia indiana. Desde sempre muito voltada ao exterior, nos seus vínculos a montante e a jusante, essa indústria, largamente nas mãos da diáspora indiana que retornou após período no exterior em que adquiriu ou ampliou a aprendizagem correspondente, revela-se uma espécie de enclave de exportaçōes, dependente de clientes estrangeiros (Balasubramanyam, Balasubramanyam, 1997). De outro lado, e na esteira disso, a trajetória do software nesse país mostrar-se-ia confinada a um padrão inferior de inovações, seja porque o envolvimento em outsourcing de empresas estrangeiras tem representado desenvolvimento de software com menos produtividade e valor, seja porque o sucesso do setor na Índia - escorado em atributos locais específicos -, na senda percorrida, não teria estimulado a exploração de alternativas (D'Costa, 2000). De todo modo, as recentes investidas de empresas como Cisco Systems, General Electric, IBM, Intel, Motorola e Texas Instruments, atraídas pela conjugação de elevadas competências profissionais e remuneraçōes baixas, talvez possam vir a representar uma substancial inflexão naquela trajetória, com a realização local de Pesquisa e Desenvolvimento.

No que se refere ao Brasil, tem sido bastante fraco o desempenho do setor de software no mercado internacional. Em 2000, por exemplo, a receita das vendas externas não ultrapassou o equivalente a $1,5 \%$ do total registrado com as vendas efetuadas no país, segundo um diagnóstico recente (Fortalecendo..., 2003). Tal situação apresenta-se em contraste com o que ocorreu na Índia, onde as exportações superaram em mais de duas vezes as vendas internas. A Tabela 2 apresenta algumas informações sobre a indústria de software desses dois países e também da China.

No que concerne a serviços, essa pífia performance parece sintoma de uma grande timidez das empresas na consolidação das suas imagens internacionais relativamente a processos, além de escalas de operação pequenas (que não rivalizam com as de concorrentes no exterior) e de um escasso engajamento efetivo na prática exportadora. No tocante a produtos, cabe assinalar que, somente "nos 
últimos anos, aparecem empresas maduras, quer do ponto de vista tecnológico, quer no seu modelo de negócio (...) [que] ensaiam agora experiências internacionais e devem trazer lições importantes para o desenvolvimento da indústria no futuro." (p. 61). As experiências internacionais indicam que avançar na exportação de produtos, a partir do desenvolvimento em certos nichos, requer investimentos duradouros e consistentes, algo que, com o vigor e a abrangência necessários, ainda é pouco observado no Brasil. Tal situação diz respeito só a algumas poucas empresas, as quais, em decorrência, lograram galgar posições em termos internacionais (Paduan, 2003). Não admira, assim, que nos anos 1990 as vendas externas de várias empresas tenham se concentrado em mercados da América Latina, com perda de competitividade nos Estados Unidos e na Europa, e que, mesmo com essa orientação, dificuldades crescentes para assegurar a presença internacional tenham sido amargadas (Duarte, 2000).

Tabela 2: A indústria de software no Brasil, na China e na Índia - 2000

\begin{tabular}{l|c|c|c}
\hline Indicadores & Brasil & China & Índia \\
\hline Vendas internas: produtos e serviços (US $\$$ bilhões) & 6,8 & 7,0 & 1,8 \\
Exportações: produtos e serviços (US\$ bilhões) & 0,1 & 0,4 & 4,0 \\
Total & 6,9 & 7,4 & 5,8 \\
\hline Pessoas atuando em software & 153.353 & 186.000 & 350.000 \\
Empresas no segmento de software & 10.713 & 10000 & $>2.800$ \\
\hline
\end{tabular}

Fonte: Fortalecendo...(2003)

De qualquer maneira, por acenar com atraentes oportunidades de negócios, o potencial do mercado brasileiro pode representar estímulos capazes de proporcionar uma inserção externa em bases mais promissoras para diferentes empresas. Note-se que o interesse nesse assunto redundou na criação, em 1993, do SOFTEX 2000, um programa do Governo Federal destinado a promover a capacitação das empresas nacionais para exportar. Vinculado ao Ministério de Ciência e Tecnologia até 1996, e desde então sob a responsabilidade da Sociedade para Promoção da Excelência do Software Brasileiro (SOFTEX), esse programa parece ter frutificado, pois empresas a ele vinculadas registraram ganhos em qualidade e competitividade que lhes propiciaram uma certa inserção internacional (WEBER, CAVALCANTI, 
ARAÚJO, 1998). Certamente a estrutura do programa, envolvendo duas dezenas de núcleos instalados em diversos estados brasileiros, teve - e segue cumprindo - um importante papel.

Essa estrutura do SOFTEX estaria a refletir o entendimento de que as aglomerações de empresas e instituições, ou clusters, têm grande importância na sustentação das atividades de alta tecnologia, pelo que tais formas organizativas representam para a difusão do conhecimento e para a inovação. Com efeito, possivelmente mais do que em outros setores, a proximidade geográfica dos agentes e a aglomeração das atividades mostram-se cruciais para o desempenho das indústrias de alta tecnologia. Há vários anos estuda-se e destaca-se a importância da concentração espacial para os processos de inovação, mesmo que alguns autores indiquem ser necessário considerar, além da influência da localização, as características internas das empresas (KOSCHATZKY, 1998). A proximidade entre os agentes mostra-se essencial porque os contatos face a face e freqüentes lubrificam consideravelmente a difusão do conhecimento e a aprendizagem, nutrindo, por conta disso, as inovações. Essa condição era evocada há mais de um século por Marshall (1979), em cuja opinião, nas aglomerações, "se alguém lança uma nova idéia, esta é adotada por outros e combinada com sugestões próprias; e assim torna-se fonte de outras novas idéias." (p. 225).

Ora, a concentração espacial é particularmente estratégica quando o conhecimento em questão é novo e objeto de transmissão tácita, mediante spillovers implicando empresas, universidades e diferentes tipos de infra-estrutura tecnológica e de conhecimento, assim como pela mobilidade de trabalhadores de elevada qualificação (AUDRETSCH, FELDMAN, 1996). Nas atividades em que a transferência do conhecimento assim se caracteriza - entre as quais desponta as de alta tecnologia, como a indústria da informática e o segmento de software -, a importância dos spillovers ajuda a entender por que a "geografia conta para a atividade inovativa e, em última instância, para a vantagem comparativa internacional." (AUDRETSCH, 1998, p. 18).

Essas questōes têm sido abordadas em diferentes estudos sobre clusters de alta tecnologia na Europa (KEEBLE, WILKINSON, 1999) e nos Estados Unidos (SAXENIAN, 1991), mostrando-se decisivo em todos os casos o papel das interligações. Nesses estudos, cooperar tem status de palavra de ordem, tendo em vista que se revela tipo de iniciativa estratégica na conformação das "regiōes de aprendizagem" [learning regions] (MORGAN, 1997). É importante assinalar, de toda maneira, que as interações não devem ser circunscritas ao nível local- 
regional, para evitar situações de confinamento [lock-in] nas trajetórias exploradas e, como decorrência, a possível deterioração dos recursos locais (MASKELL, MALMBERG, 1999; SIMMIE, KIRBY, 1998).

Esses elementos, dizendo respeito ao significado da concentração espacial e da colaboração tanto interfirma quanto implicando instituições, têm figurado na base de diversas políticas de promoção das inovações e do desenvolvimento local-regional, em vários países. A criação de parques tecnológicos e incubadoras de empresas desponta nessas iniciativas, no Brasil e no exterior (VEDOVELLO, 2000; VEDOVELLO, PUGA, FELIX, 2001).

\section{Software em Florianópolis: anatomia de um aglomerado high tech}

Florianópolis corresponde a uma das três áreas em Santa Catarina onde a indústria de alta tecnologia marca presença com certo destaque (as outras referem-se a Blumenau e Joinville, embora diferentes cidades do estado abriguem algumas atividades do gênero). Esse aglomerado possui dezenas de empresas - levantamento efetuado recentemente por Mahl (2004) detectou o funcionamento de 125 empresas - vinculadas principalmente ao segmento de software, mesmo que algumas atuem também (ou exclusivamente) em hardware.

Nicolau et al. (2002) classificaram como segue as áreas de atuação dessas empresas: hardware e software para telecomunicações; automação comercial e softwares de gestão; automação industrial e de laboratórios; equipamentos e sistemas eletrônicos de controle; softwares para projetos de engenharia; softwares para gestão da Internet; softwares diversos. Como se observa, no que toca a software, desenvolvem-se localmente diversos tipos de produtos, sendo esta uma característica que diferencia Florianópolis das aglomerações de Blumenau e Joinville, onde há concentração em softwares para gestão empresarial. De todo modo, foi em softwares para gestão administrativa, administração industrial e automação comercial, assim como em soluções para Internet, que Mahl (op. cit.) identificou os maiores números de empresas em Florianópolis.

O aglomerado registra a atuação de instituições importantes, algumas em funções de coordenação, outras exercendo papéis fundamentais em ensino e pesquisa, e um terceiro grupo - o termo "grupo" não reflete ações desvinculadas do que ocorre em outras instituições, pois algumas operam em várias frentes - que se faz notar pela incubação de empresas. 
Entre as que atuam em coordenação, deve-se realçar a Associação Catarinense de Empresas de Tecnologia (ACATE), que mantém um Condomínio Industrial de Informática. No plano do ensino e da pesquisa desponta, sem favor, a Universidade Federal de Santa Catarina (UFSC), cujas atividades no terreno das engenharias são reconhecidas nacionalmente. Foi no âmbito da UFSC que surgiu, e segue operando, a Fundação Centro Regional de Tecnologia em Informática (CERTI), uma instituição que Vieira (1995) classificou de híbrida por ser uma "fundação privada intermediária entre universidade e governo (...)" (p. 37), criada em meados dos anos 1980 para a realização de atividades ligadas a metrologia e automação, depois evoluindo a ponto de atuar na certificação ISO-9000. Foi igualmente na estrutura da UFSC que, muito mais tarde, floresceu o Centro de Geração de Novos Empreendimentos em Software e Serviços (GENESIS), uma pré-incubadora instalada no Departamento de Informática e Estatística dessa universidade sob os auspícios do Programa Geração de Novos Empreendimentos em Software, Informação e Serviços (GENESIS), do Governo Federal, que objetiva estimular estudantes e pesquisadores universitários a abrir empresas. $\mathrm{O}$ Centro de Tecnologia em Automação e Informática do SENAI (CTAI/ SENAI), implantado na primeira metade da década de 1990, também integra o rol das instituições que atuam em pesquisa.

Quanto às incubadoras propriamente ditas, a relação inclui: o Centro Empresarial para Laboração de Tecnologias Avançadas (CELTA), que viu a luz no seio da Fundação CERTI em meados dos anos 1980, hoje com o status de ser uma das maiores incubadoras de alta tecnologia da América Latina; o SOFTPOLIS, uma das unidades do Programa SOFTEX 2000 distribuídas no país; e a Incubadora MIDI Tecnológico, fruto de parceria entre ACATE e SEBRAE que frutificou no final da década de 1990. Como salienta Bizzotto (2001), as iniciativas envolvendo as incubadoras têm sido sustentadas por rede de organismos pertencentes aos governos federal, estadual e municipal e que abrange também o SEBRAE-SC e o SENAISC. A Figura 1 reúne as informações deste parágrafo e dos anteriores, com o objetivo de facilitar a visualização da estrutura do aglomerado.

Cabe assinalar que os primeiros passos da trajetória da indústria de alta tecnologia em Florianópolis remontam à década de 1960 , quando foi a criada a UFSC, mas que o efetivo impulso ocorreu principalmente a partir dos anos 1970, com a instalação da ELETROSUL e da TELESC, ligadas aos sistemas ELETROBRÁS e TELEBRÁS, pela ordem (Vieira, 1995). As primeiras empresas surgiram justamente como spin-offs de tais instituiçōes, na esteira de movimentos protagonizados por ex-quadros técnicos dessas empresas 
estatais. Isso aconteceu principalmente desde o início dos anos 1980 , em processo que adquiriu mais intensidade nos 1990 no bojo do Projeto Tecnópolis, uma iniciativa de cunho interinstitucional que, em 1993, fez surgir o Parque Alfa, onde atualmente se encontram instaladas empresas e instituições.

A expansão observada desde o início da década passada ganhou força com a vinda de diversas empresas transferidas de outros estados e com iniciativas que, se não representaram o deslocamento completo de empresas, traduziram a opção por Florianópolis no que diz respeito à ampliação das respectivas capacidades de operação (XAVIER, 1991). Esse processo não envolveu somente a área de Florianópolis (Blumenau foi igualmente implicada), mas a visibilidade maior, pelos números envolvidos e pela "movimentação" institucional protagonizada, disse respeito à Ilha de Santa Catarina.

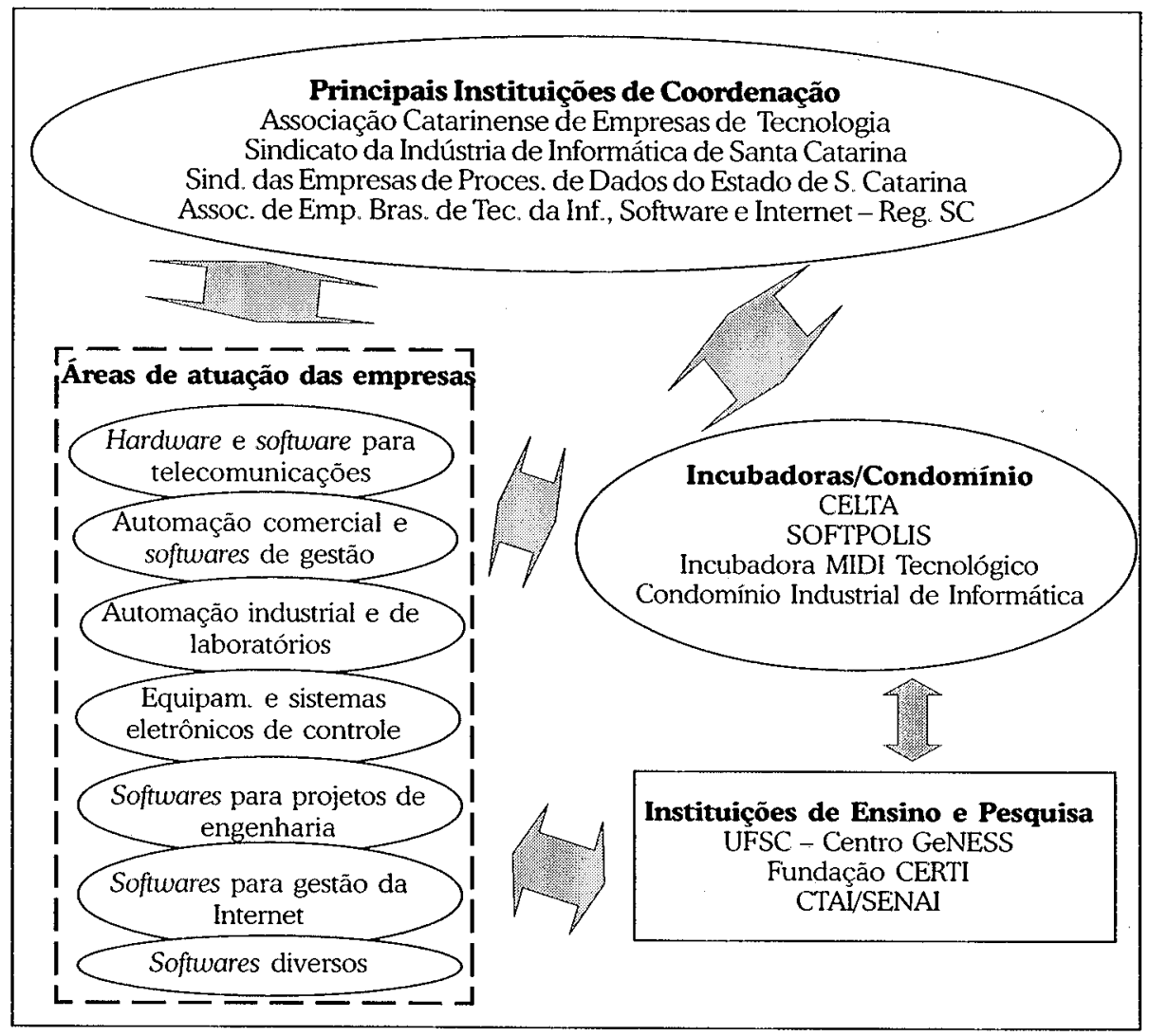

Figura 1: Estrutura do aglomerado de alta tecnologia de Florianópolis.

Fonte: elaboração do autor a partir de Nicolau et al. (2002) e de pesquisa própria. 
É sugestiva do realce alcançado por Florianópolis a indicação de James Fallows em artigo publicado no The Atlantic, em 16/8/1994, sobre o potencial de alta tecnologia do Brasil: "o Brasil está (...) cultivando um tipo de Silicon Valley - a cidade de Florianópolis, espécie de ilha-resort na costa do sulino Estado de Santa Catarina" (FALLLOWS, 1994). ${ }^{1}$ Se tal comentário parece estar perpassado pelo tom de exagero que normalmente caracteriza as avaliações muito entusiasmadas, o fato é que Santa Catarina e Florianópolis galgaram posiçōes na indústria de alta tecnologia brasileira, com destaque para o segmento de software, uma evidência que até encorajou alguns observadores a falar de uma nova tendência na economia estadual e local-regional (HASSE, 2000; QUEVEDO, 2000). Em que medida essa trajetória reverberou em inserção externa através de exportações?

\section{Procedimentos da pesquisa de campo}

A pesquisa que serviu de base para o estudo da internacionalização do segmento de software florianopolitano foi realizada junto a empresas e instituições do respectivo aglomerado de alta tecnologia. As entrevistas nas empresas, feitas em maio de 2004, foram definidas a partir de um cruzamento entre as informações apresentadas em Mahl (2004) e a listagem do censo de software realizado em 2001 pelo Ministério de Ciência e Tecnologia (obtida em <www.mct.gov.br/ Temas/info/Dsi/CensoSW/EmpSul.htm >).

A identificação das empresas exportadoras aconteceu por meio de consultas a sites na Internet e envolveu telefonemas de confirmação para as que pareciam ter clientes no exterior. Em seguida efetuaram-se entrevistas diretas, com contato pessoal. Três empresas foram abordadas dessa maneira: Complex Informática Ltda., Softplan/ Poligraph e Thermus Comércio, Serviços e Representações. Uma quarta empresa foi estudada com base em fontes secundárias, tendo em vista que a pretendida entrevista não pôde ser realizada pelo fato de o principal responsável estar quase sempre na filial instalada em São Paulo. Trata-se da Paradigma Absolute E-Commerce, cujo destaque em termos de internacionalização tornou-a objeto de uma recente dissertação de mestrado (SOHN, 2004) e de uma certả atenção, ao menos em alguns momentos, na mídia nacional. Embora o acesso a esse material não tenha compensado a entrevista frustrada, representou inegável contribuição para o entendimento da correspondente investida externa.

\footnotetext{
I "Brazil is (...) nurturing a kind of Silicon Valley - the resort-like island city of Florianópolis, off the coast of southern Santa Catarina state."
} 
As instituições com as quais se estabeleceu contato foram as incubadoras SOFTPOLIS e MIDI Tecnológico. Contudo, tendo em vista que uma das empresas visitadas (a Complex Informática Ltda.) encontrava-se instalada no mesmo prédio da incubadora CELTA, de uma certa forma foi possível conhecer alguns aspectos do modo como esta atua. Note-se que a Incubadora MIDI Tecnológico, de responsabilidade do SEBRAE-SC, fica nas dependências da ACATE (que possui, no mesmo local, um Condomínio Industrial de Informática), sendo as relações entre ambas tão estreitas que o coordenador da primeira pertencia, no período da pesquisa, ao quadro funcional da segunda. Desse modo, a entrevista nessa Incubadora acabou representando, de um modo ou de outro, pesquisa igualmente naquela Associação.

As quatro empresas identificadas para o estudo sobressaíram entre diversas outras que informaram por telefone ter só recentemente procurado iniciar algum tipo de relacionamento no exterior ou tentado comercializar seus produtos para clientes estrangeiros, sem prosperar neste tipo de iniciativa. Além das mencionadas quatro empresas, outros casos de venda internacional foram detectados. Todavia, tratava-se de vendas em volumes ínfimos e realizadas de forma absolutamente pontual, sem continuidade, apresentandose muito mais, pode-se dizer, como de caráter puramente experimental. Esses movimentos geralmente focaram países da América Latina (Colômbia, Argentina, Chile, Paraguai e Uruguai) e até da Europa (Alemanha, Itália e Portugal), às vezes por conta de viagens dos sócios ou de relacionamentos com pessoas desses locais que possibilitaram consultas a eventuais clientes. Situações como essas, se não foram numerosas, também não se revelaram escassas. Porém, nenhuma tinha ultrapassado um estágio que se poderia chamar de mera "prospecção". Perguntados nos telefonemas sobre as razões disso, os interlocutores apontaram diversas dificuldades, que serão posteriormente assinaladas no momento da análise dos resultados das entrevistas nas empresas visitadas.

\section{Internacionalização do Software Florianopolitano: estudos de caso}

Relatam-se a seguir as quatro experiências de internacionalização captadas por meio de entrevistas (três casos) e de pesquisa em fontes secundárias (um caso). 


\subsection{Complex Informática Ltda.}

As exportações dessa empresa diziam respeito, no momento da entrevista, ao software Everest, um "pacote" desenvolvido para uso educacional cujos usuários são escolas e também pessoas físicas que atuam em educação. As vendas externas, que começaram em 2000, alcançam compradores nos seguintes países: Argentina, Chile, Japão, México e Portugal.

Apesar de não representar um fluxo realmente contínuo de exportações, essa penetração externa merece realce pela diversidade de formas e pelos processos subjacentes. As vendas para o Japão tinham ocorrido por iniciativa do cliente japonês, que estabelecera uma comunicação com a Complex após uma consulta ao site da empresa. Já as vendas para os demais países decorreram da participação do proprietário em viagens organizadas com outros empresários do setor e em feiras. Na Argentina, por exemplo, a comercialização resultara de palestra ministrada pelo dono da empresa na feira em que o produto estava sendo exposto.

Esse segundo aspecto da internacionalização dessa firma remete ao papel das instituições que gravitam em torno da indústria de software local, como o entrevistado fez questão de frisar. Segundo a informação obtida, o fato de a empresa estar associada ao SOFTEX 2000 há muitos anos representou possibilidade de acesso a informações sobre mercados externos e favoreceu a participação em viagens e feiras. Isso envolveu a unidade local do SOFTEX - o SOFTPOLIS -, cujas operações permitiram (ou pelo menos facilitaram) a inserção da empresa na trama de vínculos e informações que envolve o setor em escala nacional.

Daí ter o proprietário reconhecido que estar presente no aglomerado de alta tecnologia de Florianópolis é importante para a empresa. Contudo, essa importância não foi atribuída somente ao que se conseguiu realizar em termos de vendas externas. Fazer parte do aglomerado, e principalmente estar localizado no Parque Alfa, significaria usufruir - na expressão usada - de uma espécie de "marketing coletivo", representando algo como um "selo de qualidade" ou uma espécie de "cartão de visitas". Mais do que isso, propiciaria, além de apoio operacional, benefícios ligados à "sinergia da tecnologia", derivada da freqüência de contatos entre os integrantes do Parque e das incubadoras, sobretudo em ambientes como restaurantes e cafeterias e nas conversas de corredor, como se procurou frisar.

Assim, para a Complex Informática, o ambiente em que a empresa está inserida revela-se impregnado de interações com sentido 
cooperativo. Esse aspecto foi sublinhado principalmente quando o dono mencionou um novo produto, o software Parla!, para uso em aulas e reuniões (ao estilo das teleconferências) envolvendo participantes distantes uns dos outros, indicado como futuro carro-chefe da empresa. Embora já tivesse sido objeto de lançamento no mercado brasileiro (ocasião em que logrou até ser premiado), o produto foi em seguida recolhido para aperfeiçoamento. $O$ melhoramento consistiu na introdução de novos recursos, nos quais estaria a inovação - a inovação principal desse software - relativa às especificações de uso para a área médica. Importa sobretudo ressaltar que esse aperfeiçoamento envolveu cooperação com outra empresa local, uma iniciativa que se revelou determinante para o resultado obtido.

\subsection{Softplan/Poligraph}

Essa empresa vinha exportando de forma recorrente uma das quatro soluções que compōem o seu leque de oferta de softwares. Trata-se da Solução para Administração Física e Financeira de Projetos (SAFF), destinada à gestão de projetos financiados por organismos internacionais, como o Banco Mundial e o Banco Interamericano de Desenvolvimento. Os clientes desse software são órgãos governamentais, e as vendas no exterior têm implicado a participação da empresa em concorrências públicas realizadas em outros países. As demais soluções desenvolvidas pela empresa, absorvidas domesticamente, dirigem-se, além de órgãos de governo e integrantes da estrutura da Justiça (Tribunais, por exemplo), a empresas de engenharia.

Segundo o Gerente do Projeto SAFF, a empresa exportava esse software desde 1998, quando foi lançada a sua primeira versão em espanhol. Isso resultou de desenvolvimento do produto para o Projeto de Modernização do Setor de Saúde Nicaragüense, ligado ao Ministério da Saúde daquele país. Em seguida, o software foi também utilizado - igualmente com base na venda da licença de uso no Projeto de Reforma do Sistema de Pensões, vinculado ao Instituto Nicaragüense de Segurança Social. Mais recentemente, a Softplan/ Poligraph implantou uma versão dessa solução nos Programas Multifases de Transformação Institucional do Setor de Saúde do Panamá, de um lado, e de Desenvolvimento Sustentável de Darién (uma província desse país), de outro. Essas implantações foram possíveis porque o SAFF é um produto apto à "customização", isto é, pode ser adaptado para diferentes condições de utilização em atendimento às exigências dos clientes. Naturalmente, isso requer o envio de integrantes do corpo técnico da empresa aos países dos compradores 
para a realização de levantamentos sobre a situação local; uma vez identificadas as especificidades locais, as condições encontradas são em seguida incorporadas, tornando o programa compatível com as necessidades. Tendo em vista que, além dessas atividades de adequação, a venda é acompanhada de práticas abrangendo treinamento, consultoria e manutenção dos aplicativos, não se trata somente, a rigor, de exportação de produtos, mas também de vendas externas de serviços, como acentuou o entrevistado.

Cabe assinalar que, desenvolvido pela Softplan/Poligraph desde 1993, o software SAFF já vinha registrando uma ampla utilização no Brasil, em gestão de programas de saneamento, conservação e manejo de recursos naturais e também na área de educação, em estados das regiões sul e sudeste. Quer dizer, a internacionalização veio na esteira de processo ao longo do qual a competência se consolidou em mercados internos. Na data da entrevista, a empresa considerava as possibilidades de exportação para outros países da América Latina, principalmente no MERCOSUL. Sobre a exploração de mercados na América do Norte e na Europa, entretanto, não se cogitava qualquer iniciativa: na análise do Gerente entrevistado, "não são mercados para nós...".

Outro aspecto a ser destacado é que essa empresa tem contado só com os próprios esforços no seu processo de internacionalização. De fato, frisou-se na entrevista que as exportações derivavam exclusivamente de iniciativas próprias, individuais, inexistindo qualquer influência de um, por assim dizer, "efeito aglomeração". Aliás, a localização em Florianópolis foi classificada como atributo sem importância, tanto assim que, embora instalada no Parque Alfa, a Sofplan/Poligraph, se encontrava praticamente "isolada". Na avaliação do interlocutor, operava num quase vácuo de relações locais. Todavia, diferentemente do que isso poderia significar à primeira vista, tal condição não estaria a representar problema para a empresa, como se fez questão de enfatizar.

Cabe assinalar, de todo modo, que os quadros técnicos da empresa têm contado reiteradamente com vários profissionais oriundos da Universidade Federal de Santa Catarina. Assim, em que pese o teor da entrevista sobre o papel da aglomeração no desempenho empresarial, a localização da Sofplan/Poligraph não é tão pouco significativa para as suas atividades como se parecia querer acreditar.

\subsection{Thermus comércio, serviços e representações}

As exportações da Thermus referiam-se, no momento da entrevista, ao software GetInfo.RA, uma solução para uso no setor de telecomunicações que permite às operadoras aperfeiçoar os registros 
de chamada telefônica, com melhores resultados no faturamento. Entretanto, a empresa não realizava as vendas no exterior diretamente: a comercialização ocorria através das operações do Grupo Tecnológica Informática, surgido no início dos anos 1980, sediado no Rio de Janeiro e com instalações/filiais em diferentes estados brasileiros, apresentando atividades ligadas ao tratamento de dados quer por meio de software, quer com uso de hardware.

A relação entre a Thermus e o Grupo Tecnológica teve início no final dos anos 1990, quando uma crise financeira na primeira oportunizou o envolvimento de agentes externos com base na introdução de capital, uma tarefa que acabou sendo cumprida por sócios do segundo. Desde então, a Thermus achava-se incorporada a este como unidade que desenvolve software - conforme assinalado na entrevista, era a única unidade ligada ao Grupo que desempenhava tal função -, ainda que preservasse a sua identidade (conservando a razão social de origem). Essa individualidade estava com os dias contados, entretanto. De acordo com as informações obtidas pela entrevista, até o final de 2004 o processo de incorporação formal, que já se encontrava em curso, haveria de se completar, resultando na extinção da Thermus - o modo como isso ocorreria ainda estava em estudo - e na transferência das instalações desta ao Grupo Tecnológica. As exportações realizadas - totalmente via Grupo Tecnológica, vale insistir, pois a Thermus sequer possuía área comercial - envolviam tanto produto (GetInfo.RA) - na forma de "pacote" completo, porém com soluções "customizadas" - quanto serviços, já que as vendas eram acompanhadas da prestação de suporte técnico. Os destinos vinham sendo alguns países da América Latina, como México, Bolívia, Costa Rica e Porto Rico, e (com menor expressão) também os Estados Unidos.

Assim, trata-se de internacionalização decorrente de um tipo peculiar de vínculo, sem a influência clara de qualquer "efeito aglomeração". Ou seja, a investida externa não dependia de inserção em rede de relações locais envolvendo instituições ou outras empresas. A entrevista foi clara nesse sentido, tendo-se destacado que a Thermus nunca interagiu localmente e sequer esboçou iniciativas nessa direção.

Todavia, perguntado sobre a importância da localização em Florianópolis, o entrevistado respondeu afirmativamente, ainda que isso se devesse a um único fator: a presença da Universidade Federal de Santa Catarina, origem da formação de quase todos os que trabalhavam na empresa ou que por lá tinham passado. É por isso que os únicos obstáculos para exportar, conforme reconhecido na 
entrevista, prendiam-se às dificuldades financeiras, de alguma periodicidade na empresa e de papel determinante na decisão sobre a incorporação integral ao Grupo Tecnológica. Tais crises se refletiam diretamente nas atividades de desenvolvimento de software, repercutindo no seu desempenho e, por extensão, nas vendas externas.

\subsection{Paradigma absolute e-commerce}

Essa empresa é a de maior destaque entre as que, no segmento de software instalado no aglomerado de alta tecnologia de Florianópolis, conseguiram avançar no processo de internacionalização. Fundada no final dos anos 1990, sobressaiu rapidamente no mercado nacional de soluções para comércio eletrônico quando concluiu o desenvolvimento do software Web Business Center (WBC), que "permite que uma empresa compre de seus fornecedores, venda ou se relacione com sua rede comercial e atenda consumidores a partir de um único site [na Internet]" (Exportar..., 2000, p. 25). Mas a correspondente plataforma de e-commerce é flexível, mostrando-se apta para uso não só no comércio entre empresas (business-to-business) mas igualmente nas relações governo-empresas e empresas-consumidores, ocorrendo utilização inclusive no mercado de capitais (SOHN, 2004).

Foi na aplicação em comércio eletrônico entre empresas que ocorreu a primeira exportação da empresa. Isso aconteceu em 2000, quando a Paradigma vendeu o software para o Grupo ParaRede, de Portugal. A seqüência de eventos que culminou nessa venda, abordada por Sohn (op. cit.), incluiu a indicação da Paradigma ao cliente português pelas empresas Microsoft e Externe, em resposta a um pedido de sugestão do primeiro sobre empresas capazes de oferecer uma solução business-to-business. Atendidas as expectativas, as sucessivas rodadas de negociações resultaram na venda, que ocorreu paulatinamente até 2001. Essa experiência reverberou na Paradigma, pois impulsionou a capacitação da empresa para a realização de outros negócios, sistematicamente, implicando até o desenvolvimento de outras versões do WBC.

Assinale-se que, embora a Paradigma tivesse como principais concorrentes um punhado de companhias multinacionais - entre as quais perfilavam-se nomes como Oracle e IBM -, a empresa experimentou êxito em seu posicionamento no mercado. Constituiu um marco nesse processo de internacionalização o prêmio de empresa detentora da melhor solução para comércio eletrônico no mundo concedido pela Microsoft em 2001- trata-se do prêmio Microsoft 
Certified Partner Awards. Tal premiação, que decorreu de seleção entre cerca de 800 candidatos e representou a elevação da Paradigma à condição de empresa de classe mundial, juntou-se a outras recebidas no Brasil e na América Latina e proporcionou uma grande visibilidade em termos de mídia, pelo menos em escala nacional (por exemplo, PADUAN, 2003; Empresa..., 2003).

Esse processo de internacionalização parece ter sido pouco (se tanto) influenciado pelo fato de a empresa estar situada no arranjo de alta tecnologia de Florianópolis. Tudo se passou, ao que parece, no âmbito de uma relação fundamentalmente bilateral, sem um maior envolvimento perceptível de outros atores do tecido empresarial e institucional da área. Ao ser procurada por clientes potenciais, a Paradigma simplesmente demonstrou capacidade para responder à demanda e conseguiu oferecer uma solução tecnicamente e financeiramente adequada, daí resultando as vendas ao exterior.

Parece sugestivo sobre os escassos vínculos locais o fato de a unidade central da empresa estar localizada no centro de Florianópolis, muito distante do Parque Alfa. Mais emblemático ainda é o fato de o presidente do seu Conselho Administrativo, que é quem se ocupava, no período da pesquisa, das vendas para clientes estrangeiros, passar a maior parte do tempo na filial que a Paradigma instalou em São Paulo. Motivo: "é lá que acontece o principal dos nossos negócios...", como esclareceu um funcionário quando se tentou agendar (sem sucesso, conforme indicado) uma entrevista. A rigor, é nessa escala mais abrangente que estaria a se desenrolar o essencial das relações interempresariais e institucionais que envolvem a Paradigma: essa empresa era uma das várias, de diferentes estados brasileiros, que haviam ensaiado a formação do consórcio Next, cujo objetivo era criar uma grande empresa de software a ser instalada nos Estados Unidos; de outro lado, o mencionado presidente do Conselho Administrativo da Paradigma era também o vice-presidente de exportação da Câmara Brasileira de Comércio Eletrônico.

\section{Análise e discussão}

Analisar os resultados da pesquisa de campo exige colocá-los em perspectiva, relativamente à problemática das exportações de software por países menos industrializados e à importância da "forma aglomerado" para sustentar e estimular a atuação das empresas. Ambos os temas foram abordados no início do artigo, quando se identificou a problemática geral da pesquisa. Porém, um primeiro aspecto a destacar nesta etapa de análise e discussão é que, se as experiências observadas em Florianópolis envolvem exportações de 
produtos na forma de "pacotes" - destoando do padrão de vendas externas de softuare por países menos desenvolvidos -, o fato de as soluções exportadas terem quase sempre necessitado adaptações aos tipos de uso especificados pelos clientes, e também de a comercialização ter implicado acompanhamento técnico pós-venda, mostra que essa internacionalização abrange igualmente a prestação de serviços. Pode-se falar, assim, com base nas estratégias de vendas externas mencionadas na seção anterior, de casos em certa medida híbridos. Esse traço estaria a espelhar a natureza dos produtos exportados e também as características dos clientes.

Em relação à problemática das exportações de softuare em países menos industrializados, onde geralmente há obstáculos vinculados à estreiteza dos próprios mercados internos, aos menores níveis educacionais e de formação profissional, à menor qualidade dos produtos e serviços oferecidos e às restrições na órbita da comercialização, deve-se assinalar que a presença externa das empresas pesquisadas não significa qualquer imunidade da parte delas a problemas importantes e estruturais. Com efeito, aparecem nas quatro experiências estudadas algumas das dificuldades normalmente experimentadas nos países que não se apresentam entre os principais atores do desenvolvimento e produção de software em escala mundial. Assinale-se que problemas semelhantes foram mencionados, como parte da justificativa para a ausência de exportações, por várias empresas com as quais se fez contato durante os procedimentos que resultaram na identificação dos casos de vendas no exterior.

Restrições financeiras, acompanhadas de falta de apoio e incentivos nesse terreno, foram os obstáculos mais apontados, sendo que, na esmagadora maioria das empresas contatadas e não retidas para a pesquisa - pela falta de presença externa -, esses problemas foram sempre indicados entre as principais causas do confinamento ao mercado interno ou regional. Entre as empresas visitadas, a Complex Informática Ltda. foi enfática ao destacar as limitações à atuação internacional representadas pela escassez de suporte financeiro, e a Softplan/Poligraph chamou a atenção tanto para os altos custos de adaptação dos produtos (a "customização") - tendo em vista ser necessário deslocar profissionais e efetuar levantamentos sobre as condições locais - como para as exigências financeiras das próprias vendas internacionais, já que é muito caro manter representantes comerciais que efetuem a "prospecção" de mercados no exterior acompanhados da infra-estrutura necessária à apresentação dos produtos aos clientes. 
Essas dificuldades financeiras não só representam uma manifestação local de obstáculos que se revelam estruturais na indústria de software dos países menos desenvolvidos, como remetem a uma incontornável lacuna em nível de aglomerado (e também em outros níveis, como o da administração estadual, pelo menos) envolvendo a questão do amparo financeiro. Esse problema salta aos olhos sobretudo quando se constata a importância atribuída internacionalmente a essa esfera na promoção de aglomerações produtivas de diversos tipos (SZAPIRO, ANDRADE, 2002).

Problemas ligados à oferta de mão-de-obra qualificada não foram mencionados, e nesse aspecto parece residir uma das vantagens centrais da aglomeração de Florianópolis. Entre os principais motivos da atração de empresas de alta tecnologia para essa área encontra-se, com efeito, a oferta local de recursos humanos para atividades dessa natureza. Isso evoca, antes de qualquer coisa, o papel desempenhado pela Universidade Federal de Santa Catarina. Uma das mais recentes empresas a se instalarem localmente - a Navita (que desenvolve soluções de tecnologia da informação), cuja presença no aglomerado foi anunciada em meados de 2003 - admitiu a sedução representada por esse atributo: sua vinda teria sido influenciada pela "proximidade com a Universidade Federal de Santa Catarina, um dos grandes centros de formação de mão-de-obra." (NAVITA..., 2003).

Entretanto, a julgar pelas manifestaçōes das empresas entrevistadas, parece limitar-se a esse fator a principal vantagem da aglomeração, onde se carece até de efetivas ações institucionais destinadas a proporcionar uma maior familiarização das empresas com mercados de padrão internacional, mais seletivos e exigentes que os internos, um requisito para a intensificação das investidas internacionais. Portanto, como arranjo técnico-produtivo e institucional, a aglomeração não exibe - na ótica dos entrevistados - um desempenho realmente capaz de impulsionar a internacionalização das empresas, talvez excetuando-se, entre as experiências repertoriadas, o caso da Complex Informática. Essa opinião sobre as limitações da aglomeração parece, de fato, pertinente, ainda que se possa dizer que, ao menos de forma indireta, a localização representa alguma influência positiva, pois o proclamado padrão dos recursos humanos formados na UFSC provavelmente contribuiu para o alcance de um patamar de qualidade apto a favorecer as exportações.

Carência é termo que se aplica também aos vínculos cooperativos locais, pois a Complex Informática foi o único caso pesquisado em que, de alguma forma, esse tipo de relação teve realçada a sua 
existência e a sua importância. Tudo indica serem escassas, limitadas e pobres as interações na aglomeração, um problema que Campos e Nicolau (1996) já haviam deplorado no tocante à "ausência de complementaridade mais estrita entre os principais integrantes do núcleo científico e do núcleo técnico-industrial." (p. 18). Esses autores constataram que os vínculos existentes entre os dois núcleos não transcendiam a órbita da formação de mão-de-obra, uma restrição nada desprezível, ainda mais quando se considera a importância que as empresas de alta tecnologia costumam atribuir às interações locais (KARAGOZOGLU, LINDELL, 1998). Desse modo, Florianópolis não destoa do quadro geral que estaria a prevalecer na indústria de software brasileira, marcado pela resistência das empresas às ações de natureza coletiva (PADUAN, 2003).

A pouca importância atribuída pelas empresas ao papel desempenhado pela aglomeração nas suas respectivas performances exportadoras, assim como o caráter bastante rarefeito das interações locais, permite falar da experiência de Florianópolis como uma espécie de contraponto em relação ao que costuma ser apresentado na literatura sobre aglomerações de alta tecnologia em vários países. Realmente, conforme sublinhado no final da segunda seção do artigo, a concentração espacial das atividades, representando grande proximidade geográfica entre os agentes, revela-se importante para as indústrias de alta tecnologia devido às possibilidades de transferência de conhecimento (com base em inter-relações diversas) e às sinergias (envolvendo vínculos colaborativos) que tais configurações oportunizam. Em Florianópolis, a opinião predominante entre as empresas entrevistadas sobre o papel da aglomeração pode estar espelhando uma incapacidade das próprias empresas para aproveitar as vantagens potenciais da área e/ou uma insuficiente projeção das instituições locais, cujas atividades deveriam torná-las aptas para promover interações e apoiar/estimular o setor em questão, em direção ao tecido empresarial. Assim, enquanto área de alta tecnologia, Florianópolis estaria se caracterizando muito mais como uma aglomeração, por assim dizer, "passiva", isto é, marcada pela presença de algumas externalidades importantes porém pouco (ou quase nada) permeada por interações dinâmicas e conseqüentes. Isso pode ser interpretado como evidência de incapacidade local para inocular o sentido de ação conjunta nesse aglomerado, o que pode estar restringindo um aproveitamento mais amplo das possibilidades existentes.

É verdade que, mesmo na contramão do que se preconiza em estudos internacionais, a escassa ação coletiva - assim como as defi- 
ciências em termos de apoio financeiro, entre outros problemas não impediu que as empresas investigadas realizassem vendas no exterior. Entretanto pode-se considerar que, em certo sentido, os casos de exportação analisados são fortuitos, no sentido de que não decorreram do funcionamento de uma estrutura voltada à promoção da presença externa das firmas. Portanto, não surpreende que se repita em Florianópolis o fraco desempenho exportador ostentado pela indústria de software no Brasil como um todo. Não há, efetivamente, nada que mereça a referência a uma "orientação exportadora" no aglomerado florianopolitano, não obstante a presença de incubadoras - inclusive de uma unidade do Programa SOFTEX 2000 -, de um parque tecnológico e de instituições que, em conjunto, poderiam representar um alicerce capaz de projetar o setor no exterior, como ocorre em experiências internacionais.

\section{Conclusão}

Referindo ao triplo objetivo deste estudo, cabe assinalar conclusivamente que: a) Florianópolis abriga empresas de software com presença internacional, uma posição outorgada pela venda externa de produtos acompanhados de alguns serviços; b) que isso resultou de procedimentos que, embora diversos, teriam refletido tão-somente o próprio desempenho empresarial; c) e que a "forma aglomerado" pouco influenciou as experiências observadas. As dificuldades para exportar assinaladas pelas empresas envolvem principalmente questões financeiras. O escasso suporte nessa área compromete a divulga* ção das empresas e de seus produtos no exterior, o que torna as atividades de marketing e comercialização especialmente problemáticas.

Logo, afigurar-se-ia de grande importância a efetivação de iniciativas especialmente voltadas para as referidas esferas - marketing e comercialização. Essas medidas, prioritárias sob todos os aspectos, devem se revelar capazes de ampliar a exposição internacional dos produtos e serviços e também representar um efetivo suporte técnico à prática exportadora. Naturalmente, postular algo nessa perspectiva significa reconhecer a existência de espaço para providências de estímulo e sustentação, concebidas e implementadas em escala nacional (talvez no bojo das reformas para o setor de software com as quais o Governo Federal acenou em abril de 2004, como parte de iniciativas mais amplas de política industrial, cf. Rossi, 2004) e/ou local-regional. No que concerne ao plano nacional, além das medidas específicas para software (que devem favorecer avanços em termos de qualidade e custos, entre outros aspectos), é essencial preservar os contornos mais amplos de um ambiente econômico e 
institucional positivo e estimulante. Em relação ao plano local-regional, seriam especialmente bem-vindas algumas articulações interinstitucionais que resultassem, por exemplo, em melhor acesso das empresas a serviços de consultoria e, sobretudo, em amparo financeiro para uma adequada "prospecção" de mercados fora do Brasil.

\section{Referências bibliográficas}

AUDRETSCH, D. B. Agglomeration and the location of innovative activity. Oxford Review of Economic Policy, 14(2), p. 18-29, Summer 1998.

AUDRETSCH, D. B., FELDMAN, M. P. RGD spillovers and the geography of innovation and production. The American Economic Review, 86(3), p. 630-640, June 1996.

BALASUBRAMANYAM, A., BALASUBRAMANYAM, V. N. Singer, services and software. World Development, 25(11), p. 1857-1861, 1997.

BIZZOTTO, C. E. N. Rede de incubadoras: a rede catarinense. Blumenau: FURB, 2001. Obtido em: <www.acate.com.br/kit_imprensa/ArtigoReCEPET.doc>. Acesso: maio 2004. CAMPOS, R. R., NICOLAU, J. A. Redes em CETT: a tentativa de criação do pólo de Florianópolis. Texto para Discussão, n 5 , maio 1996.

CORREA, C. C. Strategies for software exports from developing countries. World Development, 24(1), p. 171-182, 1996.

D'COSTA, A. P. Export growth and path-dependence: the locking in of innovations in the software industry. $4^{\text {th }}$ INTERNATIONAL CONFERENCE ON TECHNOLOGY POLICY AND INNOVATION, ago. 2000, Curitiba, International Center for Software Technology/ Pontifícia Universidade Católica do Paraná. Proceedings...(CD ROM).

. Uneven and combined development: understanding India's software exports. World Development, 31(1), p. 211-226, 2003.

DUARTE, V.C. Empresas brasileiras de software: uma análise comparativa entre paulistanas e software houses de outras cidades. III SEMINÁRIO DE REDE PMEs MERCOSUL, abril 2000, Fortaleza, UFC/Redes PMEs Mercosul/SEBRAE. Anais... (CD ROM).

EMPRESA catarinense desbanca gigantes em e-commerce. Ciência e Cultura, 55(2), p. 50, abr.jun. 2003.

EXPORTAR software é com a Paradigma. Diário Catarinense, p. 25, 3 dez, 2000.

FALLOWS, J. Consider Brazil. The Atlantic online. Obtido em: <www.theatlantic.com/ unbound/ffnpr/jf40816.htm > . Acesso: ago. 2003.

FORTALECENDO a economia do conhecimento no Brasil, China e Índia: a trajetória de três indústrias de softuare. Pesquisa MIT/SOFTEX, 2003. Disponível em: <www.softex.br> Acesso: maio 2004.

HASSE, G. Da obscuridade ao estrelato. Gazeta Mercantil/Balanço Anual Santa Catarina, p. 45-46, ago, 2000.

HIGH tech in China. Business Week, p. 44-56, Oct. 2002.

KARAGOZOGLU, N., LINDELL, M. Internationalization of small and medium-sized technology-based firms: an exploratory study. Journal of Small Business Management, 23(1), p. 44-59, Jan. 1998.

KEEBLE, D., WILKINSON, F. Collective learning and knowledge development in the evolution of regional clusters of high technology SMEs in Europe. Regional Studies, 33(4), p. 295-303, June 1999. 
KOSCHATZKY, K. Firm innovation and region: the role of space in innovation processes. International Journal of Innovation Management, 2(4), p. 383-408, Dec. 1998.

LOHR, S. Many new causes for old problem of jobs lost abroad. The New York Times, Feb. 15, 2004. Obtido em: <www.nytimes.com> Acesso: fev. 2004.

MAHL, M. O perfil da indústria de informática de Florianópolis em 2003. Florianópolis, 2004. Monografia (Curso de Graduação em Ciências Econômicas) - Universidade Federal de Santa Catarina.

MARSHALL, A. Principles of economics. $8^{\text {th }}$ ed. London: Macmillan, 1979.

MASKELL, P., MALMBERG, A. Localised learning and industrial competitiveness. Cambridge Journal of Economics, 23, p. 167-186, 1999.

MORGAN, K. The learning region: institutions, innovation and regional renewal. Regional Studies, 31(5), p. 491-503, 1997.

MOST Siemens software jobs moving East. The New York Times, Feb. 16, 2004. Obtido em: <www.nytimes.com> Acesso: fev. 2004.

NAVITA pretende ganhar mercado externo em 2004. NetComex, 14 jul 2003. Obtido em: $<$ www.netcomex.com.br/noticias/materia.asp?a=6573> Acesso: maio 2004.

NICOLAU, J. A et al. Alta tecnologia em Santa Catarina: a nascente indústria de software. In: VIEIRA, P. F. (org.). A pequena produção e o modelo catarinense de desenvolvimento. Florianópolis: APED Editora, 2002, p. 171-205.

OECD. OECD information technology outlook 2000: ICTs, e-commerce and the information technology. Paris: OECD Publications Service, 2000.

PADUAN, R. Tesouro escondido. Exame, p. 36-41, 25 jun. 2003.

QUEVEDO, S. SC cresce em alta tecnologia. Diário Catarinense, p. 24, 3 dez. 2000.

RAI, S. In India, a high-tech outpost for U.S. patents. The New York Times, Dec. 15, 2003. Obtido em: <www.nytimes.com> Acesso: dez. 2003.

ROSSI, C. Setor de software pode ter reformas. Folha de S. Paulo, p. B-11, 3 abr. 2004.

SAXENIAN, A. The origins and dynamics of production networks in Silicon Valley. Research Policy, 20, p. 423-437, 1991.

SIMMIE, J., KIRBY, M. Innovation and the theoretical bases of technopole planning. Progress in Planning, 49(3/4), p. 159-197, 1998.

SOHN, A. P. L. Análise do processo de formulação das estratégias de internacionalização de duas empresas que desenvolvem e exportam software em Santa Catarina. Florianópolis, 2004. Dissertação (Mestrado em Relações Internacionais para o Mercosul) -- Universidade do Sul de Santa Catarina.

SZAPIRO, M., ANDRADE, M. Internacionalizaçāo de arranjos e sistemas de MPME. In: LASTRES, M. M. L. et al. (coords.). Interagir para competir: promoção de arranjos produtivos e inovativos no Brasil. Brasília: SEBRAE: FINEP: CNPq, 2002, p. 225-248.

VEDOVELLO, C. Aspectos relevantes de parques tecnológicos e incubadoras de empresas. Revista do BNDES, 7(14), p. 273-300, dez. 2000.

VEDOVELLO, C., PUGA, F. P., FELIX, M. Criação de infra-estruturas tecnológicas: a experiência brasileira de incubadoras de empresas. Revista do BNDES, 8(16), p. 183-214, dez. 2001.

VIEIRA, S. A indústria de alta tecnologia em Florianópolis. Florianópolis, 1995. Dissertação (Mestrado em Geografia) - Universidade Federal de Santa Catarina.

WEBER, K. C., CAVALCANTI, J. C., ARAÚJO, E. E. R. de. The Brazilian software industry and the 21st Century economy. SOFTEX, 1998.

XAVIER, M. A informática migra para Santa Catarina. Veja Santa Catarina, p. 8-11, jun. 1991 . 